\title{
A Study on Higher Vocational College Students' Academic Procrastination Behavior and Related Factors*
}

\author{
Yusheng Ying ${ }^{\mathrm{a}}$, Wei Lv ${ }^{\mathrm{b}}$ \\ ${ }^{a}$ Department of Basic Courses, Binzhou Polytechnic, Binzhou, Shandong, China \\ ${ }^{b}$ Department of Social Sciences, Binzhou Polytechnic, Binzhou, Shandong, China
}

\begin{abstract}
The purpose of this study was to examine academic procrastination behavior among higher vocational college students and explore the predictability of such variables as academic self-efficacy, academic frustration tolerance, achievement motivation, grade and gender. 440 students from two higher vocational colleges were taken as subjects. The results showed that (1) $41.6 \%$ of the subjects exhibited a high level of academic procrastination. (2) Students in Grade Three procrastinated more often than students in Grade One. (3) Male students showed more academic procrastination behavior than female students. (4) Academic self-efficacy, academic frustration tolerance and motive to avoid failure were desirable predictive variables for academic procrastination. (5) High procrastinators' academic self-efficacy, academic frustration tolerance and motive to approach success were significantly lower than those of low procrastinators', but their motive to avoid failure was significantly higher than that of low procrastinators'.
\end{abstract}

Index Terms: Higher Vocational College Students; Academic Procrastination Behavior; Related Factors

(C) 2012 Published by MECS Publisher. Selection and/or peer review under responsibility of the International Conference on E-Business System and Education Technology

\section{Introduction}

The word procrastinate comes from the Latin word procrastinatus: pro (forward) and crastinus (of tomorrow).And it has been defined as a kind of behavior in which an individual leaves a feasible, important deed planned beforehand to another time without any sensible reason [1] . It is widespread among adolescents and adults and takes place in everyday behaviors. There are five different forms of procrastination: (1)academic procrastination, referred to delaying academic tasks such as doing homework, handing in term paper or preparing for examinations at the last minute; (2) decisional procrastination, defined as inability to make timely decisions; (3) neurotic procrastination, defined as a tendency to postpone decisions about important matters in

\footnotetext{
* The research is supported by 11th Five Year Plan of Education and Science of Shandong province in China under Project 2008 GZ004.

Corresponding author:

E-mail address: ${ }^{\mathrm{a} Y \text { Yingyusheng@163.com; }}$ ' $\underline{\text { Lvwei2004967@163.com }}$
} 
individual life; (4) life routine procrastination, described as having problems in scheduling and accomplishing routine life tasks on time; (5) compulsive procrastination, defined as decisional and life routine procrastination occurring in the same person.

Despite the fact that procrastination exists in all kinds of daily tasks, academic procrastination is a common phenomenon on college campuses. It is estimated that the percentage of college students who procrastinate on school-related tasks range from as low as $22 \%-33 \%$ [2-3] to as high as $95 \%$ [4].Given the prevalence of procrastination, it has become a subject of much interest to scholars and administrators.

A careful review of procrastination literature reveals that procrastinating academic tasks can lead to not only objective consequences such as lower grades, higher course withdrawals, poorer classroom attendance and student dropouts; but also some subjective consequences such as emotional discomforts. Previous research indicates that when a person is aware that he is procrastinating, he may experience a number of negative feelings including self-deprecation, embarrassment, guilt, sense of fraudulence, tension, panic, and overall anxiety. In a word, procrastination is associated with a maladaptive life style, resulting in serious personal and social effects which will reinforce feelings of lack of personal competence; besides, it is known that prolonged exposure to stress may eventually do harm to one's mental and physical health. Therefore, academic procrastination is regarded as a self-defeating behavior which has short-term benefits but long-term costs [5].

Although a few of studies have found significant relationships among the subjects' procrastination tendency, self-efficacy, achievement motivation and frustration tolerance, they confined to the general procrastination domain only, which does not follow the opinion that procrastination is a domain-specific phenomenon. Since the studies on academic procrastination in China have just started, analyses on the relationships of procrastination behavior with demographic and psychological variables are insufficient, more empirical studies should be carried out to enhance our scientific understanding of procrastination. Thus, our goals of the current study are to examine the prevalence of higher vocational college students' academic procrastination behavior and explore its relationships with students'academic self-efficacy, academic frustration tolerance and achievement motivation. Our findings may have profound implications for procrastination interventions.

\section{Method}

\subsection{Subjects}

A total of 440 undergraduates from two higher vocational colleges in Binzhou city participated in the study. The sample contained 252 females and 188 males. 201 were freshmen and 239 were juniors. The subjects ranged in age from 17 to 22 years with the mean age of respondents being 19.2 years $(\mathrm{SD}=2.78)$. The subjects completed all measures during the study.

\subsection{Measures}

1) Academic Self-Efficacy: The students' academic self-efficacy was measured by Academic Self-Efficacy Scale. It has 7 items rated on a five-point scale from strongly disagree (1) to strongly agree (5). The higher the subjects' scores are, the higher the subjects' academic self-efficacy is. Previous studies have proved that it had acceptable coefficients of reliability and validity [6]. This scale was found to have a coefficient Alpha of 0.82 in this study.

2) Academic Frustration Tolerance: Academic Frustration Tolerance Scale was used to measure subjects' academic frustration tolerance. It contains 14 items. Subjects respond to each item on a four-point Likert scale. The homogeneity reliability in the original study is 0.80 [7]. It was found to have a coefficient Alpha of 0.78 in the present study.

3) Achievement Motivation: The students' achievement motivation was measured using the Achievement Motivation Scale modified by Ye [8]. This instrument is composed of two subscales of fifteen items each, 
assessing two types of motivation named motive to approach success and motive to avoid failure. The split-half reliability coefficient for this scale is 0.77 .

4) Academic Procrastination: Aitken Procrastination Inventory was utilized to measure subjects' academic procrastination. It is a self-report inventory measuring trait procrastination among college students. It contains 19 items that use a five-point scale ranging from False (1) to True (5). A total scale score is calculated by summing the 19 items together. High scores on this scale are associated with procrastination. A previous study showed it had high validity and strong reliability applied to college students sample in China. Its Cronbach Alpha coefficient is 0.80 and test-retest reliability is 0.70 . It had a significant negative correlation with subjects' general self-efficacy $(\mathrm{r}=-0.40, \mathrm{P}<0.01)$ [9]. And it was found to have a coefficient Alpha of 0.81 in the current study, which is consistent with the coefficient Alpha of 0.82 reported by Aitken in her original study [10].

\subsection{Procedure}

During the study, the subjects were given the following scales in sequential order: Academic Self-Efficacy Scale, Academic Frustration Tolerance Scale, Achievement Motivation Scale, and Aitken Procrastination Inventory. To ensure anonymity, only code numbers were placed on these questionnaires. At the completion of all the scales, the subjects were fully debriefed. For analysis of the data, SPSS 16 program was used. In the research, the meaningfulness level was set as minimum 0.05 , and other meaningfulness levels were indicated as 0.01 and 0.001 .

\section{Results}

The students' mean score on Aitken Procrastination Inventory was 52.27 with a standard deviation of 12.14. According to a previous study [11], a median split of procrastination scores was performed, thereby making two groups, low procrastinators (procrastination score of 21-52) with 216 participants (49.1\%) and high procrastinators (procrastination score of 53-83) with 183 participants (41.6\%). Thus, it can be concluded that $41.6 \%$ of the students engage in frequent academic procrastination.

A two-way MANOVA $(2 \times 2)$ was performed to determine both interaction and main effects for grade and gender. Significant main effects were found for grade $(\mathrm{F}=5.55, \mathrm{P}<0.05)$, and gender $(\mathrm{F}=6.88, \mathrm{P}<0.01)$. The main effect for grade revealed that juniors showed more academic procrastination behavior than freshmen. The main effect for gender reflected the fact that male students procrastinated more frequently than female students. But there was no significant interaction between grade and gender in academic procrastination $(\mathrm{F}=2.08, \mathrm{P}>0.05)$. Means and standard deviations for academic procrastination by gender and grade are presented in Table I.

Table 1. Descriptive Statistics of Students' Academic Procrastination Scores by Gender and Grade

\begin{tabular}{ccccccc}
\hline \multirow{2}{*}{ Gender } & \multicolumn{3}{c}{ Grade One } & \multicolumn{3}{c}{ Grade Three } \\
\cline { 2 - 7 } & $\boldsymbol{N}$ & $\boldsymbol{M}$ & $\boldsymbol{S D}$ & $\boldsymbol{N}$ & $\boldsymbol{M}$ & $\boldsymbol{S D}$ \\
\hline Male & 77 & 51.68 & 14.84 & 111 & 56.23 & 10.19 \\
Female & 124 & 50.26 & 11.62 & 128 & 51.35 & 13.23 \\
Total & 201 & 50.81 & 12.95 & 239 & 53.77 & 12.04 \\
\hline
\end{tabular}

A Pearson product-moment correlation was also performed to investigate the relationship between the students' academic procrastination and academic self-efficacy, academic frustration tolerance, motive to approach success and motive to avoid failure. The results of correlation analysis revealed that the students' academic procrastination behavior was negatively correlated with their academic self-Efficacy, academic frustration tolerance and motive to approach success, but positively with their motive to avoid failure, which indicates that students with low academic self-efficacy, low academic frustration tolerance and low motive to 
approach success may procrastinate more frequently. The correlation coefficients were $-0.56,-0.54,-0.36$ and 0.41 respectively $(\mathrm{P}<0.001)$.

In order to test the effects of demographic variables and psychological variables on academic procrastination, a two-step hierarchical regression analysis was conducted and the results can be seen in Table II. Results from the first step of these analyses indicate that gender and grade accounted for approximately $5.9 \%$ of the variance in students' self-reported level of academic procrastination $(\mathrm{F}=13.66 \mathrm{P}<0.001)$. Grade $(\beta=0.21, \mathrm{P}<0.001)$, gender $(\beta=-0.13, \mathrm{P}<0.05)$ were both significant predictors of academic procrastination.

Table 2. Hierarchical Regression Analysis for Variables Predicting Academic Procrastination (N=440)

\begin{tabular}{lccc}
\hline \multicolumn{1}{c}{ Predictor } & \multicolumn{3}{c}{ Academic Procrastination } \\
\cline { 2 - 4 } & $\boldsymbol{\beta}$ & $\boldsymbol{t}$ & $\boldsymbol{\Delta R}^{\mathbf{2}}$ \\
\hline Step1 & & & 0.059 \\
Gender & -0.13 & $-2.37^{*}$ & \\
Grade & 0.21 & $2.53 * *$ & \\
Step2 & & & \\
Academic Self-Efficacy & -0.35 & $-8.41^{* * *}$ & \\
Academic Frustration Tolerance & -0.28 & $-5.89 * * *$ & \\
Motive to approach success & -0.02 & -0.37 & \\
Motive to avoid failure & 0.13 & $2.96 * *$ & \\
\hline$* \mathrm{P}<0.05 * * * \mathrm{P}<0.01 ; * * * \mathrm{P}<0.001$ & &
\end{tabular}

Results from the second step of these analyses (see Table II) indicate that after the demographic variables were controlled, students' psychological variables could explain nearly $39 \%$ of the variance in students' academic procrastination $(\mathrm{F}=58.98, \mathrm{P}<0.001)$. Academic self-efficacy was the strongest individual predictor of academic procrastination $(\beta=-0.35, \mathrm{P}<0.001)$. The students' academic frustration tolerance $(\beta=-0.28, \mathrm{P}<0.001)$ and motive to avoid failure $(\beta=0.13, \mathrm{P}<0.01)$ also entered the final regression model. But the students' motive to approach success $(\beta=-0.02, \mathrm{P}>0.05)$ failed to be a significant individual predictor.

An independent sample $t$ test was performed between high and low procrastinators to examine the differences in their academic self-efficacy, academic frustration tolerance and achievement motivation. The results are shown in Table III. It can be seen that there were significant differences between the two groups. High procrastinators' academic self-efficacy, academic frustration tolerance and motive to approach success were lower than those of low procrastinators', but their motive to avoid failure was higher than that of low procrastinators'.

Table 3. The Comparison of Psychological Variables between the Two Groups

\begin{tabular}{|c|c|c|c|c|c|}
\hline & \multicolumn{2}{|c|}{$\begin{array}{c}\text { High } \\
\text { Procrastinators }(\mathrm{N}=183) \\
\end{array}$} & \multicolumn{2}{|c|}{$\begin{array}{c}\text { Low } \\
\text { Procrastinators }(\mathrm{N}=216)\end{array}$} & \multirow[t]{2}{*}{$\mathbf{t}$} \\
\hline & $M$ & $S D$ & M & $S D$ & \\
\hline $\begin{array}{l}\text { Academic } \\
\text { Self-Efficacy }\end{array}$ & 18.64 & 3.17 & 22.19 & 3.04 & $-8.81 * * *$ \\
\hline $\begin{array}{l}\text { Academic } \\
\text { Frustration Tolerance }\end{array}$ & 34.48 & 4.44 & 37.59 & 4.63 & $-5.17 * * *$ \\
\hline $\begin{array}{l}\text { Motive to } \\
\text { Approach Success }\end{array}$ & 38.59 & 5.88 & 40.21 & 5.01 & $-2.39 *$ \\
\hline $\begin{array}{l}\text { Motive to } \\
\text { Avoid Failure }\end{array}$ & 39.73 & 6.62 & 36.85 & 5.71 & $3.28 * *$ \\
\hline
\end{tabular}

$* \mathrm{p}<0.05 ; * * \mathrm{p}<0.001 ; * * * \mathrm{p}<0.001$ 


\section{Discussion}

\subsection{Levels and Prevalence of Academic Procrastination}

In the study, we found that about $41.6 \%$ of our subjects engaged in frequent academic procrastination. This result is consistent with previous studies among Chinese college students [12]. Although the measures and methods used to assess academic procrastination differ in different studies, the conclusion is almost the same, which suggests that academic procrastination is common among college students in China.

\subsection{Demographic Variations and Academic Procrastination}

We also found that the main effect of grade was significant, students of Grade Three tended to display more procrastination behavior on academic tasks than students of Grade One, which is somehow in line with a previous research on Chinese college students [13]. One possible reason can be that there are great differences in educational contexts and academic demandings between high schools and colleges in China. Compared with high school students, college students have more freedom and many social activities. Therefore, the freshmen who have just finished compulsory education may spend some time in getting familiar with the college educational environments and contexts. Once they become accustomed to the teaching system and are more familiar with the school setting, their level of adjustment and commitment to school tasks decreases instead of increasing [14]. Another possible reason may be due to the fact that for most students, Grade Three is an important stage in their college life. Many of them are at the key point of survival in college. They are eager to complete their third year and receive their diploma. Many of the students carry with them past obligations, such as courses that have been left to the third year, failed courses which have to be retaken, and most especially they begin to look for information about future jobs. In short, the third year students are under a cognitive overload and are pressed for time [15]. Thus, compared with the freshmen, students in Grade Three may face more contradictions and conflicts. Lacking of strategies to deal with them successfully and failing to allocate their time and energy reasonably can partly account for the reasons why juniors procrastinated on school-related tasks more often.

The current study shows that academic procrastination behavior differed in respect of gender variation. Male students reported significantly higher levels of academic procrastination than female students. But the literature concerning gender differences on academic procrastination is somewhat inconsistent. Some of the studies have emphasized that procrastination behavior did not change according to gender [16]; others have suggested that women were at more risk for being procrastinators than men [17]. However, the present findings are supported by the studies carried out by Senecal et al. [18]. One possible interpretation for current findings may be that female students are more likely to experience negative emotions such as guilt, anxiety and self-blame caused by procrastination behavior, so they will be more likely to use behavioral self-control and time management strategies to balance their study and life. Thus they may procrastinate less on academic tasks.

\subsection{Academic Procrastination and Psychological Factors}

In the present study, we found that students' academic self-efficacy, academic frustration tolerance and motive to avoid failure were significant predictors of academic procrastination. Academic self-efficacy invariably emerged as the best significant predictor. High procrastinators' academic self-efficacy, academic frustration tolerance and motive to approach success were lower than those of low procrastinators', while motive to avoid failure was higher than low procrastinators'. These findings imply that academic self-efficacy plays an important role in students' learning process. According to Bandura's theory [19], self-efficacy expectations may impact people's behavior through cognitive, motivational, affective, and selection processes. Expectations of 
self-efficacy are the most powerful determinants of behavioral change, because self-efficacy expectancies determine the initial decision to perform a behavior, the effort expended and persistence in the face of obstacles and adverse situations. Thus, students who are confident in their capabilities to accomplish academic tasks may deal better with uncertainty, distress, and conflict. They tend to choose to perform more challenging academic tasks, set higher goals, exert greater effort and stick to them, while individuals who report low self-efficacy may perceive a task as more difficult than reality, which, in turn, may create anxiety and stress. They are more likely to avoid tasks which they have less confidence in their ability to successfully complete. Therefore, people who have lower levels of academic self-efficacy will be more likely to procrastinate and delay working on academic tasks than the ones who are with higher levels.

\subsection{Educational Implications}

The present findings do provide some valuable implications for educational practice. For one thing, teachers and administrators should be aware of the negative consequences of academic procrastination, identify the various reasons students used for their behavior and help them to get rid of it. For another, interventions aimed to enhancing students' self-efficacy and frustration tolerance may serve to decrease procrastination behavior among students. Therefore, a procrastinator can start with the easiest tasks, then proceeds from there to more rigorous and demanding tasks. Success in the easier tasks is likely to motivate and encourage him to deal with more difficult tasks and hence building up confidence in his ability to tackle academic matters. Furthermore, group trainings and workshops which aim to equip students with the strategies and skills of effective time management, planned studying, reasonable expectations for academic work, emotion regulation and problem solving should be organized and these will be beneficial in decreasing the level of students' procrastination tendency.

\section{Conclusion}

The study attempts to extend previous research by exploring the prevalence and the related variables to academic procrastination. The main findings are as follows:

Academic procrastination is widespread among higher vocational college students in China. More than $40 \%$ of the students postpone or delay academic tasks at a high level.

Demographic variables such as gender and grade level may affect students' academic procrastination behaviour. Male students, high-grade students always involve higher levels of academic procrastination.

Academic self-efficacy, academic frustration tolerance, motive to avoid failure are desirable predictive variables for academic procrastination, and there are significant differences in students' academic self-efficacy, academic frustration tolerance, motive to approach success and motive to avoid failure between high and low procrastinators. Compared with low procrastinators, the high ones always have lower levels of academic selfefficacy, academic frustration tolerance and motive to approach success, but higher levels of motive to avoid failure. These findings indicate that enhancing students' academic self-efficacy, academic frustration tolerance and decreasing their motive to avoid failure are effective measures to help students overcome academic procrastination.

\section{References}

[1] Grecco P R. A cognitive-behavioral assessment of problematic academic procrastination: development of a procrastination self-statement inventory. Unpublished PHD. Fresno: California School of Professional Psychology, 1984. 
[2] Ely D D, Hampton J D. Prediction of procrastination in a self-pacing instructional system. New Orleans: Paper presented at the meeting of the American Educational Research Association, 1973, LA (ERIC Document Reproduction Services No. ED 0755501).

[3] Rosati P A. Procrastinators prefer PSI. Education Research and Methods, 1975, 8: 17-19.

[4] Ellis A., Knaus W J. Overcoming procrastination. New York: Institute for Rational Living, 1977.

[5] Tice D M, Baumeister R F. Longitudinal study of procrastination, performance, stress and health: The costs and benefits of dawdling. Psychological Science, 1997, 8:454-458.

[6] Ning X H. Research on the Relationship between Frustration Tolerance and Family Function of College Students. Unpublished Master's Thesis. Jiangxi: Jiangxi Normal University, 2008 (in Chinese).

[7] Xiao Z L. On Academic Self-efficiency and Achievement Motivation of College Students. Journal of Hubei Polytechnic University, 2003, 18(4): 70-73 (in Chinese).

[8] Ye R M, Hagtvet K A. Measurement and Analysis of Achievement Motivation. Psychological Development and Education, 1992, 3:14-16 (in Chinese).

[9] Chen X L, Dai X Y, Dong Q. A Research of Aitken Procrastination Inventory Applied to Chinese College Students. Chinese Journal of Clinical Psychology, 2008, 16(1):22-23(in Chinese).

[10] Aitken M E, A Personality Profile of the College Student Procrastinator. Unpublished PhD dissertation. Pittsburgh: University of Pittsburgh, 1982

[11] Shane G O, Christin G B, Charles A D. Overcoming Procrastination: The Effect of Implementation Intentions. Journal of Applied Social Psychology, 2008, 38(2):366-384.

[12] Zhao X Zhang C H. The Current Situation of academic Procrastination among undergraduates. Journal of Shandong University of Technology: Social Sciences, 2009, 25(2):90-92(in Chinese).

[13] Zhang J K, Chen L, Huang Y Y. Undergraduates' Academic Procrastination and Predictive Variables. Journal of Ningbo University: Education, 2009, 31(4):54-59(in Chinese).

[14] Rosário P, Costa M, Mourão R. et al. Procrastination, SRL and Math Achievement. Academic Exchange Quarterly, 2007, 11 (4), 23-28.

[15] Miriam S, Yehuda P. The Effect of Procrastination on Multi-Drafting in a Web-Based Learning Content Management Environment. Interdisciplinary Journal of E-Learning and Learning Objects, 2010, 6:345349.

[16] Watson D C. Procrastination and the five-factor model: A facet level analysis. Personality and Individual Differences, 2001, 30(1):149-158.

[17] Washington J A. The Relationship between Procrastination and Depression among Graduate and Professional Students across Academic Programs: Implications for Counselling. Unpublished PhD Dissertation. Texas: Texas Southern University. 2004.

[18] Senecal C, Koestner R, Vallerand R J. Self-regulation and academic procrastination. The Journal of Social Psychology, 1995, 135(5):607-619.

[19] Bandura A. Self-efficacy: Toward a unifying theory of behavioral change. Psychological Review, 1977, 84: 191-215. 